\title{
A human rights approach to disability assessment
}

\author{
Lisa Waddington $^{\mathrm{a}}$ and Mark Priestley ${ }^{\mathrm{b}}$ \\ ${ }^{a}$ Faculty of Law, Maastricht University, Maastricht, The Netherlands \\ ${ }^{\mathrm{b}}$ School of Sociology and Social Policy, University of Leeds, Leeds, UK \\ Email: lisa.waddington@maastrichtuniversity.nl
}

(Received 7 November 2019; revised 21 July 2020; accepted 19 August 2020)

\begin{abstract}
Disability assessments play a key role in welfare states but are increasingly contested, not least for their compatibility with the United Nations Convention on the Rights of Persons with Disabilities (CRPD). This paper draws on evidence of global governance and assessment practices in 34 European countries, the largest international study to date. The paper reflects on the model of disability in the CRPD and its implications for disability assessment, drawing on the work of the CRPD Committee. The paper also examines examples of promising practice in assessment in European countries and concludes by identifying elements of a CRPDcompatible approach. Disability assessments must be underpinned by both a social-contextual concept of disability and a human rights approach. Administrative attribution of disability status based on categorical diagnosis or individual functioning alone is incompatible with this approach. This approach challenges the historic individualization of disability assessments and the knowledge relationships underpinning them.
\end{abstract}

Keywords: Disability; needs assessment; welfare rights; human rights

Assessments of disability status play a key role in welfare states. They are used to determine who is, and is not, eligible for public support in cash or in kind. They determine who is exempt from participation in the labour market, who is entitled to social security payments, who gets practical help at home, and so on. In this way, disability assessments serve strong functions of budgetary gatekeeping and social validation, as technologies of government and bio-power (Garsten \& Jacobsson, 2013). Nevertheless, the concepts and methods that underpin them remain complex, contested and elastic. These vary among different welfare regimes, over time and between policy functions (Mabbett, 2005; Stone, 1985).

At least three drivers for change to disability assessments have been evident over the past decade. These are budget driven, technically driven, and rights driven. First, during a period of rising welfare costs and austerity, many established welfare states have revised their administrative definitions of disability, and associated assessment criteria, to limit public expenditure by limiting eligibility to disability benefits (Barr et al., 2010; David \& Duggan, 2006). Second, during the same period, there have been attempts to adapt disability assessment protocols to the developing technical language of the World Health Organization's International Classification of Functioning (ICF) (Brage, Donceel, \& Falez, 2008). A third driver of change has been the widespread ratification by states of the United Nations Convention on the Rights of Persons with Disabilities (CRPD) since 2008. Disability assessment systems, like other domestic disability policies, need to be brought into line with this framework of international human rights law.

This paper explores the elements of a CRPD-compatible approach to disability assessment. Based on an analysis of the Concluding Observations and General Comments issued by the UN Committee on the Rights of Persons with Disabilities, it considers what a CRPD-compatible method of disability

\footnotetext{
(c) The Author(s), 2020. Published by Cambridge University Press on behalf of Social Policy Association. This is an Open Access article, distributed under the terms of the Creative Commons Attribution licence (http://creativecommons.org/licenses/by/4.0/), which permits unrestricted re-use, distribution, and reproduction in any medium, provided the original work is properly cited
} 
assessment is. Good practice and principles are then elaborated through an exploration of disability assessments in European states.

The paper builds on the most extensive international review of disability assessments to date, conducted in 28 European Union Member States and 6 candidate or associated countries, under the auspices of the Academic Network of European Disability experts (ANED) in 2017 (Waddington, Priestley, \& Sainsbury, 2018). Prior to this, the most comprehensive European review of assessment methods was commissioned by the Council of Europe and covered 21 countries, but this preceded the CRPD (Pozzo et al., 2002). More than a decade on from the CRPD, there remains a lack of empirical research linking it to the topical challenge of disability assessment.

The first part of this paper explores the concept of disability embodied by the CRPD and its relation to other models of disability. It then reviews the approach taken to disability assessment by the UN CRPD Committee, examining its findings and recommendations systematically, including its Concluding Observations to European states. The second part considers examples of practice in European states, based on country reports commissioned from 34 national researchers for the ANED study. The paper concludes by synthesising 12 guiding principles for a CRPD-compatible approach to disability assessment.

\section{The UN Convention and the concept of disability assessment}

The CRPD is a global human rights treaty that aims "to promote, protect, and ensure the full and equal enjoyment of all human rights and fundamental freedoms by all persons with disabilities, and to promote respect for their inherent dignity." Its scope is broad and it is not our intention to review it here, but to examine its implications for the design and implementation of disability assessment systems (for a more detailed discussion of the Convention see, Kayess \& French, 2008; Lawson, 2006; Waddington, 2009).

The concept of disability embodied by the CRPD is relational. The Convention does not define disability, but recognizes that persons with disabilities include those "who have long-term physical, mental, intellectual or sensory impairments" and who encounter barriers which hinder their "full and effective participation in society on an equal basis with others" (Preamble, recital (e) and Article 1). This concept requires some elaboration in order to appreciate its implications for disability assessment.

\section{What does the CRPD approach to disability mean for assessment?}

Disability is a contested concept, and much has been written about its definition and modelling (Altman, 2001, 2014; Oliver, 1990; Oliver \& Barnes, 2012). The distinction, found in the CRPD, between people with impairments and disabling barriers was inspired by historic claims from the disabled people's movement calling for a social interpretation, or social model, of disability. From this perspective, "Disability is something imposed on top of our impairments, by the way we are unnecessarily isolated and excluded from full participation in society" (Union of the Physically Impaired Against Segregation, 1976, p. 3). Participation barriers, rather than impairments, are the units of analysis and "disabled people are not the subject matter of the social interpretation of disability" (Finkelstein, 2001, p. 1). Such an approach contrasts sharply with individual models, in which "disabilities" are viewed as personal attributes that can be assessed independently of environmental factors (eg. based on functional capacity or medical criteria).

The CRPD, whilst often described as reflecting the "social model" (Kakoullis \& Ikehara, 2018), is not fully consistent with this approach. Its use of the term "persons with disabilities," rather than "disabled people," is somewhat at odds with the social model construct, and the latter phrase "better reflects the social model as it is societal and environmental factors that disabled people with impairments" (Kakoullis \& Ikehara, 2018). Kayess and French (2008, p. 21) have noted that "the CRPD typically uses the term 'persons with disabilities' where conceptually 'persons with impairments' is meant" and it is "therefore difficult to construe the CRPD strictly in accordance with the social model," whilst noting that this model has nevertheless had an "enormous influence" on the development of the CRPD (Kayess \& French, 2008, p. 7). 
An alternative perspective is that the CRPD offers a distinctive "human rights model" of disability (Degener, 2016, 2017), although this term is open to diverse interpretation as numerous writers have referred to "rights" models, "civil rights," "minority group rights" or "human rights" models of disability throughout the evolution of the CRPD (Fleischer \& Zames, 2005; Kanter, 2003; Kelemen \& Vanhala, 2010; Rioux \& Carbert, 2003; Stein \& Stein, 2006; Vanhala, 2015). For example, Quinn et al. (2002) argued early in that process that:

In essence, the human rights perspective on disability means viewing people with disabilities as subjects and not as objects. It entails moving away from viewing people with disabilities as problems towards viewing them as holders of rights. Importantly, it means locating problems outside the disabled person and addressing the manner in which various economic and social processes accommodate the difference of disability - or not, as the case may be.

As this illustrates, human rights models tend to place more emphasis on persons than the social model does, while retaining the concept of environmental causation. For example, Degener's (2017) main emphasis is on persons with impairments (as rights holders), while the social model concept of barriers, echoed in the CRPD text, is reduced to a subset of "discrimination" against such persons. As she notes, the CRPD Committee has embraced the term "human rights model," but its interpretation by states, and its implications for disability assessment, remains unclear. Human rights models give rise to a paradox their focus is on persons (rights holders) but "disability" arises from attitudinal and environmental barriers (discrimination). In light of the CRPD, the real challenge for disability assessment systems is how to respect a more person-centred approach without re-individualizing the concept of disability. This is a tension we address in this paper.

While the language of the CRPD was inspired by the social model, interpreted through a human rights lens, it also has much in common with the ICF typology (Kazou, 2017). The ICF uses "disability" loosely, as an umbrella term, in an attempt to integrate different models of disability and to encompass elements of bodily impairment, activity limitation and participation restriction, as well as an environmental dimension (Fougeyrollas, Noreau, \& Boschen, 2002). A recent international joint statement on developing inclusive social protection systems echoes this:

In order to comply with the CRPD, disability assessments should not only consider impairment and activity limitations, but also the attitudinal and environmental barriers faced by persons with disabilities, as well as their support requirements (International Labour Organisation \& international Disability Alliance, 2019).

Nevertheless, the CRPD cannot be conflated with the ICF. They serve different purposes. The former is a prescriptive human rights instrument, while the latter is a descriptive classification instrument. The balance between persons and barriers is not neutral in a human rights context and, hence:

In line with the principles and vision of the CRDP [sic], disability assessment mechanisms must concentrate on participation restriction and on support needs of the disabled person more than on her/ his impairment or functional limitations. This implies also that these mechanisms take the environment into account, most often overlooked in assessments. (Arnould et al., 2012, p. 4, emphasis added)

Madden et al. (2011) articulated this distinction in the Australian welfare system, positioning the CRPD as "a philosophical vision" and ICF as a technical language requiring adaptation to "particular policy settings" (see also, Francescutti, 2011; Francescutti et al., 2011). Applying general principles to the complexities of practical administration is difficult though. For example, Bickenbach et al. (2015) highlight how challenging it is to standardize an assessment of "capacity to work" across the "enormous variety of work requirements and kinds of employment situations." Technical application of ICF has involved the development of a Disability Assessment Schedule (WHODAS 2.0), intended as "a 
standardized cross-cultural measurement of health status" using basic questionnaires (Üstün, Kostanjsek et al., 2010; Üstün, Chatterji, \& et al., 2010), but this is neither targeted at a policy function nor does it engage with the framework of the CRPD.

To summarize, the broad idea of assessing disability in terms of person-environment interactions is consistent with the CRPD, the social model and human rights models of disability and the ICF. The social model acknowledges people with impairments but focuses on barriers. The human rights model focuses on persons but acknowledges barriers. The ICF offers a language to describe people, participation and environments. Since disability arises in interactions between persons and barriers, disability assessment should focus on this interaction. Assessment mechanisms should be animated by the spirit of the CRPD, but they require technical elaboration, and they need to be tailored to specific policy functions.

\section{What does the UN Committee say about disability assessment?}

Despite its broad scope, the CRPD contains no guidance on disability assessment as a gateway to state support, other than requiring that rehabilitation services be "based on multidisciplinary assessment of individual needs and strengths" (Article 26). There is an obligation on States parties to "ensure access... to social protection programmes and poverty reduction programmes," but no indication of how "disability-related needs" or "disability-related expenses" might be determined (Article 28). It is therefore necessary to look beyond the CRPD text to its interpretation.

The progress of State parties in implementing the CRPD is reviewed periodically by the responsible UN Committee, the Committee on the Rights of Persons with Disabilities. States submit reports, which are often supplemented by shadow reports received from civil society organizations and national human rights institutes. The Committee raises issues, to which States respond, before engaging in dialogue at public hearings and, finally, issuing Concluding Observations and recommendations. The document trail from this process is published in the UN human rights treaty database and provides a rich insight into the Committee's evolving concerns and interpretations over the past decade (Office of the High Commissioner for Human Rights, n.d.). The Committee has repeatedly expressed concerns about disability assessment in its Concluding Observations - both regarding the definitions of disability used and the assessment processes employed. We review these two broad concerns below in relation to European states. All citations refer to the Committee unless otherwise specified.

\section{Contextualizing and de-medicalizing disability assessments}

First, the UN Committee has highlighted the conceptual approach underpinning disability assessments, drawing on the definitions and concepts outlined earlier to underline the need for a contextual understanding of disability and a human rights approach. Specifically, the Committee has expressed recurrent concerns about assessments that focus on individual impairment rather than on interactions with social environments. For example, regarding Hungary, it expressed concern "that definitions of disability and persons with disabilities in the State party's legislation focus on the impairments of an individual rather than on the barriers he/she faces" (Committee on the Rights of Persons with Disabilities, 2012, para. 10). Similarly, in addressing Lithuania, the Committee was concerned that "the definition and understanding of disability in State party laws and regulations focuses on the individual impairment, thereby neglecting the social and relational dimension of disability, including in particular, the barriers faced by persons with disabilities" (2016b, para. 5). It recommended that Czechia amend its legislative definitions "to make explicit reference to the barriers faced by persons with disabilities" (2015b, para. 8). In a more concrete example, the Committee recommended to Croatia that "benefits aiming at alleviating increased costs arising from disability should be based on an assessment of the individual's support needs" rather than on a degree of impairment assessed in isolation (2015a, para. 44).

The underlying message is that any definition of disability framing an assessment mechanism should reflect a social-contextual rather than an individualized approach. The assessment should consider the 
barriers that a person encounters and their needs. Considering this, it is also relevant to highlight the principle of participation by disabled people and their organizations in assessment and policy design. For example, in the cases of Belgium and Cyprus, the recommendation to adopt a human rights model of assessment was accompanied by advice to consult with disabled people's organizations (2014, para. 8; 2017a, para. 6). Grouping these themes together, for illustration, the recommendation made to Latvia was to:

ensure that disability determination is based on a human rights model of disability, includes an assessment of needs, will and preferences of the individuals concerned, ..., and focuses on the elimination of barriers and the promotion of full and effective participation of persons with disabilities in society. (2017b, para. $7(\mathrm{a})$ )

An important subset of concerns about individualization and de-contextualization in disability assessment concerns the inappropriateness of medicalized assessments. For example, the Committee noted that "disability continues to be defined through a medical perspective" in Italy (2016a, para. 5), while it was concerned "by the use of medical assessment of disability" in Portugal (2016d, para. 7). In several cases, the Committee cautioned against the application of a "medical model" in disability assessment, as in the cases of Latvia (2017b, para. 6), Luxembourg (2016c, para. 6) and Serbia (2016e, para. 53). To underline this point with an example from outside Europe, the Committee stated explicitly in its Concluding Observations to Mauritius that definitions of disability reflecting the medical approach are "incompatible with the concept of disability in the Convention" (2015d, para. 5). This has significant implications for the design of disability assessment systems.

The nesting of medicalization within broader concerns about individualization mirrors the formulation of the social model of disability. Indeed, its principal author, Mike Oliver, observed that: "In short, for me, there is no such thing as the medical model of disability, there is instead, an individual model of disability of which medicalization is one significant component" (Oliver, 1995, p. 31). In practice, physicians are often involved in disability assessments in European social security systems (Wind, Dekkers-Sánchez, \& Godderis, 2016). This raises the question of whether medical knowledge is applied inappropriately to the assessment of disability as a social situation, as part of a wider individualizing tendency, underpinned by the absence of a social or human rights approach.

Assessments that de-contextualize the person from their environment are at odds with the interactive concept of disability and, thereby, individualizing. This is most apparent where medical assessments rely on categorical diagnoses of impairment, in isolation from a consideration of disabling barriers. Such assessments are not compatible with the CRPD approach. Words to this effect were included in the Concluding Observations addressed to Belgium (2014, para. 7,8), Czechia (2015b, para. 5), Cyprus (2017a, para. 5), Montenegro (2017c, para. 6) and Slovakia (2016f, para. 11,12). In addition, a medical diagnostic approach may exclude certain categories of impairment and, thereby certain groups of persons, from eligibility for assistance, as in the case of "those with psychosocial disabilities" in Hungary, for example (2012, para. 12). To paraphrase a repeated refrain in the Committee's Concluding Observations, disability assessment must be based on a socially contextualized model of disability, while medical knowledge, on its own, is insufficient to determine the extent of disability or human need.

\section{Consistency of approach and application}

A second area of concern in the Committee's Observations is that a "human rights model" of disability should be applied to disability assessments consistently. Thus, in response to the United Kingdom, the Committee observed with concern "the lack of consistency across the State party in the understanding of, adapting to and applying the 'human rights model' of disability and its evolving concept of disability" (2017d, para. 6). To Austria, the Committee noted that "there are different concepts of disability across the State Party's laws and policies" (2013, para. 8). This, in turn, has led the Committee to become critical 
of differing definitions of disability leading to differences in access to benefits. For example, regarding Italy, it noted "that there are different definitions of disability across sectors and regions leading to disparity in access to support and services" (2016a, para. 5).

References to the need for a human rights approach across broad legislation or policy, were found in the Concluding Observations issued to Cyprus (2017a, para. 6), Montenegro (2017c, para. 7), Slovakia (2016f, para. 12), and the United Kingdom (2017d, para. 7(c)). The latter was also advised, specifically, to ensure that eligibility criteria and assessments for specific named benefits were "in line with the human rights model of disability" (2017d, para. 59(c)). Similarly, the Committee recommended to Luxembourg that criteria for social protection measures and access to services should be "in line with the human rights model of disability" (2016c, para. 7). The technical challenge here, by implication, is that states should seek to balance a consistently broad concept of disability against the variable policy functions to which different assessment mechanisms might be applied, and across different regions in the case of federal states.

The Committee's concerns have been translated into substantive policy recommendations towards several states. For example, Italy was advised to "adopt a concept of disability in line with the Convention and ensure legislation is enacted that incorporates the new concept in a homogeneous manner across all levels and regions of government and territories" (2016a, para. 6). Similarly, Lithuania was recommended to "amend the legal definition of disability in accordance with the criteria and principles provided in articles 1-3 of the Convention and [ensure] that it effectively [applies] the amended legal definition in all laws and regulations" (2016b, para. 6). Comparable recommendations were made to Austria (2013, para. 9), Germany (2015c, para. 8(a)) and Portugal (2016d, para. 8).

Linked to these calls for consistency have been calls for improved training in the CRPD and its understanding of disability. For example, the Committee called on the United Kingdom to ensure that assessments were "in line with the human rights model of disability, and that those who conduct the assessments are qualified and duly trained in that model" (2017d, para. 57(c)). Adopting a rights-based approach, applying this consistently, and ensuring that professionals are appropriately trained were recurrent themes in the Committee's observations.

To summarize, a systematic textual analysis of the UN treaty database reveals how the Committee on the Rights of Persons with Disabilities has used its dialogue with States parties to fill the hiatus resulting from a lack of direct reference to disability assessment in the text of the CRPD. States should adopt a rights-based approach, understanding disability as the product of encounters with barriers that create a disabling environment. Assessment criteria should follow the same approach, and this should be applied consistently across the range of policy areas and geographic regions. The Concluding Observations provide strong pointers towards the elements of a CRPD-compatible approach and indications of how they might be applied to legislation, implementation and professional practice. The Concluding Observations also suggest that existing disability assessments in European States often:

- adopt a medicalized or deficiency-oriented model of functioning and capacity, while neglecting the social and relational dimension of disability;

- focus on a person's impairments, skills and capabilities, rather than the barriers that they face in context;

- use diagnostic criteria that exclude some categories of persons, particularly persons with psychosocial or intellectual impairments;

- fail to establish appropriate definitions of disability in legislation, at national and regional levels, or across sectors;

- are applied inconsistently in practice, or lack the support of adequate or appropriate training, leading to disparities in access to support and services.

\section{Promising practices in disability assessment}

In light of the conceptual analysis, the second part of this paper considers examples from the country reports commissioned to chart the range and diversity of disability assessments used in Europe to 
identify promising practice. These reports provided information on 190 disability assessment mechanisms in 34 European countries and across the range of policy functions, including access to disability benefits in cash and in kind. In-depth analyses were then conducted on three assessment mechanisms in each country (102 case studies), focused on public registration of disability status, access to "invalidity" pensions, ${ }^{1}$ and long-term social care, while covering a variety of categorical, functional and needs-based assessment methodologies. The country experts were also invited to identify examples of promising practice in disability assessment. Based on this extensive evidence base, collected in 2017, the following sections present examples to illustrate four broad elements of a CRPD-compatible approach.

\section{Assessing disability as human need in context}

An underpinning concern of this paper has been the challenge posed to the historical individualization of disability assessment by the CRPD's promotion of a social and contextual model of disability, framed within a human rights approach. In some countries, there is evidence of changes to assessment criteria and processes that reflect an emerging recognition of the social-contextual understanding of disability, either in addition to medical criteria or partially replacing them.

Some of the most promising practices were evident in needs-based assessments, which are more commonly used to determine eligibility for in-kind benefits (such as social care) than for cash benefits (such as "invalidity" pensions). For example, in Greece, a new Law on Reform of Support Structures in Primary and Secondary Education (FEK102 A'/12.06.2018) saw a shift from categorical diagnostic assessment to holistic needs-based assessment in determining eligibility for additional support for children within mainstream educational settings, and extended responsibility for assessment beyond medical experts to involve interdisciplinary networks. In England and Wales, the approach to needs assessment for adult social care is underpinned by a principle of "well-being" set out in the Care Act 2014 (s 1(2)), and defines need in a holistic way, allowing for flexibility and discretion in the interpretation of real-life, outcome-based criteria, rather than relying on categorical or functional activity criteria in isolation. This allows for a multidisciplinary approach, by encouraging the use of expertise from any relevant profession, as well as wider networks of community support of the person being assessed. Although there have been significant implementation issues arising from funding cuts to social care, the assessment methodology itself is well-conceived (Carter, 2017).

By contrast, assessments for access to cash income maintenance benefits or general disability status recognition (eg. admission to a public disability register, which is itself a gateway to benefits) tend to rely on more categorical diagnostic assessments, or standardized tests of physical and mental function, conducted in isolation from social context. Such examples are contrary to a CRPD-compatible approach. For example, in at least nine countries, assessment for an "invalidity" pension was based primarily on medical diagnosis of a named condition or medical assessment using a Barema-type method, an "arbitrary ordinal scale which attaches progressive percentage values to define disability" (Council of Europe, 2002, p. 13). In a similar number of states, assessment for "invalidity" benefit was based on a functional test of ability to carry out specified tasks or activities. Only in a few states did disability assessment address economic loss directly, meaning that the degree of reduced earning capacity is taken into account (eg. France, Netherlands). For this policy function, assessments that combined impairment, functional and environmental perspectives were the exception.

To illustrate this exception, in Denmark, disability pensions (Førtidspension) are usually awarded following a procedural assessment which involves engagement in a sustained rehabilitation process, rather than a one-off claim assessed against fixed criteria (Bengtsson, 2018). If a disabled person is unable to find work, the municipal job centre tries to facilitate adaptations, internships or/and referral towards

\footnotetext{
'Invalidity' is the historic term used in the EU Mutual Information System on Social Protection (MISSOC) to classify benefits that 'support those who through long-term sickness or disability are unable to undertake paid employment', as required under Part II of the International Labour Organization's Invalidity, Old-Age and Survivors' Benefits Convention, 1967 (No. 128).
} 
medical treatment, to assess and boost employability. Medical evidence alone is not sufficient to assess eligibility and, in some cases, the rehabilitation process can last up to 5 years before a decision to award a pension is taken. While the assessment system has been criticized for its behavioural conditionality, it does contain some design elements that are promising, notably its social-contextualization of disability assessment for a policy purpose (in this case, assessing employment capacity and barriers to employment in an employment context, holistically and over time).

\section{Involving disabled people and their organizations}

Involvement of disabled people and their organizations in "the development and implementation of legislation and policies" is one of the general obligations under CRPD (Article 4(3)), and the Concluding Observations of the CRPD Committee indicate that such involvement is needed when planning changes to disability assessment mechanisms.

It is also vital that individuals can play an active part in their own disability assessment - that they are acknowledged as experts by experience and engaged in assessing their own situation. Numerous states facilitate the involvement of those who are being assessed, or their representatives, through a selfassessment identifying the impact disability has on their daily life. In some cases the individual plays a more active role. For example, in the Austrian State of Tyrol, disabled persons and their peers are directly involved in the evaluation of the need for personal assistance, regarding their current living situation and the disabling barriers they face (Flieger \& Naue, 2018). A peer counsellor from the Centre for Independent Living helps the applicant identify the number of hours of personal assistance required and supports the application to the Regional Government with a written justification. The case worker who decides on the award of the benefit then takes this into account when determining the level of funding. The wider significance of this example is the need for peer-to-peer supported self-assessment and training for disabled people in this regard, notably from disabled people's organizations (see, Priestley, 1998).

There are numerous examples of the involvement of disabled people's organizations in reform of disability assessment systems. For example, in Czechia, disabled people's organizations, including the Government Board for People with Disabilities and the Czech Disability Council, participated in preparing new assessment guidelines for the Care Allowance (a non-insurance-based social security benefit). The Ministry of Labour and Social Affairs also worked with Czech disabled people's organizations to address acute staff shortages at the Medical Assessments Service, reaching agreement to eliminate long delays by removing the need for physical medical examinations in some cases (Šiška, 2018). While the advice of disabled people's organizations was not always followed by the Czech authorities, their input contributed to efficiency and a partial de-medicalization of the assessment process.

Neither of these examples from Austria and Czechia involved a radical or transformative effect on the disability assessment system. In both cases, the movement towards a CRPD-compatible approach was partial and incremental at best. Nevertheless, they illustrate how the direct involvement of disabled people and their organizations, in practical ways, can help to de-medicalize assessment norms, increase dignity in the process, and assert the capacity of individuals to engage with decisions about their lives within existing assessment mechanisms. They also point to the potential for more radical collaborative reforms.

\section{Reducing complexity and promoting consistency of approach}

One criticism of disability assessment processes, outlined earlier, is that they lack consistency, thereby creating inequities, complexity, and barriers for people seeking access to benefits and services. The following attempts to improve access by reducing complexity were identified in Belgium and France.

In the Flanders region of Belgium, the establishment of "integrated youth care" introduced a single point of access known as the "intersectoral access portal" (intersectorale toegangspoort) (De Bruycker, 2018; Diels \& Van Puyenbroeck, 2015). The portal allows the integration of applications for disability support from the Flemish Agency for Disabled Persons (VAPH) within the general youth system, which includes mental healthcare and child and family services. For example, a child who is blind and has a 
mental health condition, no longer has to apply for separate benefits from different service providers. The promising elements here include disability mainstreaming, as well as simplification of the application process and assessment journey.

In France, local departmental offices for disabled persons (maisons départementales des personnes handicapée) also serve as single entry points for assessments based on socio-medical criteria (Secrétaire d'Etat auprès du Premier ministre chargée des Personnes handicapées, n.d.). Assessment is carried out by a multidisciplinary team to identify what is needed to compensate for limitations in activity or to overcome restrictions in participation (in the ICF terminology) to achieve personal goals and to fulfil rights and entitlements. This facilitates application for a wide range of supports (education, employment, housing and other services) via a "personalized compensation plan" (plan personnalisé de compensation), adjudicated by the Commission for the Rights and Independence of Persons with Disabilities. This holistic assessment also provides a gateway to the Disability Compensation Benefit which covers additional costs of living with disability (Nicolas \& Ebersold, 2018). In this example, the promising element is a common assessment portal providing access to multiple supports, as well as social contextualization, personalization and acknowledgement of rights.

\section{Increasing quality, transparency, and accountability}

Many of the examples highlighted promising practices relevant beyond the specific field of disability benefits. For example, while it is good practice in all public administration to ensure that citizens have easy access to good information about the system and their rights, in the case of disability assessments and benefits, it is vital to ensure that such systems are accessible for users. Accessibility needs to be provided for in all elements of the assessment process, including transport, physical infrastructure and information formats. System improvements that reduce the administrative burden of form filling, meetings and reading may have added value in the case of disability assessments.

For example, in Latvia, applicants for the general disability register, which is used to determine eligibility for a disability identity card, are able to access information and data related to their disability assessment through e-government service portals provided by national and local government (Podzina, 2018). This enables direct communication and data exchange, reducing meetings and the administrative burden on claimants and the State Medical Commission for the Assessment of Health Condition and Working Ability.

Non-governmental organizations, including disabled people's organizations, play a role in simplifying and interpreting information and advice on disability assessments in several states. For example, in Czechia, the Human Rights League provides user-friendly information related to the rights of disabled persons, such as how to apply and appeal decisions related to the disability pension (Šiška, 2018), while a major part of the caseload of Citizens Advice in the UK is occupied with advice on disability assessments (Citizens Advice, 2017).

Clear and consistent information is important for assessors too. There were some cases where official guidance and assessment criteria appeared to be entirely absent, resulting in a high reliance on professional discretion. Examples included a lack of guidance for drawing up medicalized opinions on incapacity for work in Austria, or the lack of a standardized assessment tool for establishing care needs in Ireland. By contrast, in Hungary, in the context of supported housing, assessors must complete an accredited 30-hour training module on "complex needs assessment methodology and practice," supported by a 68-page guide and a 22-page data sheet covering key areas affecting quality of life and their indicators, and highlighting the kind of individual difficulties that might be encountered by people during the assessment process (Gyulavári \& Horváth, 2018). There is inevitably some trade-off between complexity and clarity of process, but the promising element here is the accreditation of detailed training that acknowledges the disabling barriers that people may face during assessment, as well as more widely.

Reforms consistent with a human rights model often challenge established professional norms, particularly those framed historically by medicalized knowledge. To address this in Malta, all medical assessors are interviewed by the Executive Director and Commissioner of the Commission for the Rights 
of Persons with Disability to ensure that they are conversant with the principles underlying the CRPD. In addition, they receive guidance on applying the eligibility criteria (Bezzina, Camilleri-Zahra, \& Gauci, 2018). Malta is a very small country, making this targeted intervention possible at the national level, but the practice illustrates the potential to introduce a human rights model directly into the powerknowledge discourse of assessment systems.

As the preceding examples illustrate, the incorporation of a social-contextual perspective and a human rights approach into disability assessment systems may, or may not, result in radical change. There are also some elements that would constitute good practice in any aspect of public administration but have added salience for disabled persons. More fundamentally though, the CRPD poses some deep challenges to existing systems of disability assessment - either because it requires a paradigm shift in conceptualization or because it challenges existing institutional-professional power relations within the system.

The analysis so far suggests that, in line with the CRPD and examples of "good practice," public authorities should:

- Base the design of disability assessments on a social and human rights model of disability, and incorporate this approach into the practical implementation of such assessments.

- Support the active participation of disabled persons in generating the evidence on which their individual disability assessments are made, for example, through the availability of peer-supported self-assessment.

- Involve multidisciplinary expertise within the disability assessment system, including human rights expertise.

- Provide accessible and user-friendly information for disabled applicants and claimants, using adaptable media, and covering application processes, eligibility criteria, appeal and support options, as well as information on the entitlements to which the assessment leads.

- Reduce the administrative burden on applicants (and systems) by eliminating duplicative or multiple (methods of) assessments, thereby increasing consistency and transparency in the process.

- Consult with and involve disabled people's organizations and human rights bodies in the design and regular review of disability assessments.

\section{Towards a CRPD-compatible disability assessment system}

The final part of this paper synthesizes from the preceding analysis a set of 12 guiding principles for a CRPD-compatible disability assessment system. These reflect the wide-ranging principles and rights found in the CRPD and the good practices in disability assessment identified in European countries.

First, the design and conduct of disability assessments should be guided by the eight general principles that "animate" the CRPD in Article 3. These include equality of opportunity and non-discrimination, which run through the Convention like a red thread, while also receiving specific attention in Article 5. The remaining principles include dignity; individual autonomy; full and active participation and inclusion; respect for difference; and accessibility. Equality between men and women, and "respect for the evolving capacities of children with disabilities," are also addressed in Article 3 CRPD. A CRPDcompatible disability assessment system should be animated by these core principles, and a system that breaches them would contravene the CRPD. Moreover, disability assessment should be conducted in a dignified way, beginning from an assumption of choice and autonomy, for both adults and children, with the goal of achieving full participation in society without discrimination.

Second, the rights enshrined in the CRPD apply to disability assessment systems at local and regional level, as well as to those carried out under the auspices of national government. Article 4 CRPD affirms that the Convention "extend[s] to all parts of federal States without any limitations or exceptions." The general obligations found in Article 4 CRPD require states to abolish discriminatory practices and "take into account the protection and promotion of the human rights of persons with disabilities in all policies and programmes," and ensure that all public authorities and institutions act accordingly. 
Third, disability assessments should consider the interactions between "persons with long-term physical, mental, intellectual or sensory impairments" and the "various barriers that hinder their full and effective participation in society on an equal basis with others" (Article 1 CRPD). The assessment of impairment alone is not a substitute for the assessment of disability in the social context. The CRPD concept of disability is interactive, arising between persons with rights and the disabling barriers they encounter. Disability assessment should focus on this.

Fourth, the assessment should be conducted in a way that is accessible, in accordance with the obligations of Article 9 CRPD, and should provide for "reasonable accommodation" where needed. This includes providing (accommodated) access to any buildings used, and to all forms of information and communication used in the assessment process, including application forms and assessment tools. Any provisions or practices which prevent individuals from being supported during the assessment, where this is needed for an impairment-related reason, such as through sign language interpretation or personal assistance, should be removed.

Fifth, disability assessment processes must recognize the legal capacity of persons with disabilities on an equal basis with others (Article 12 CRPD). This means that "the rights, will and preferences of the person" should be respected, and that safeguards should be available to prevent abuse. Such safeguards must be "free of conflict of interest and undue influence," involve minimum restriction, and be proportional and tailored to the individual's circumstances. Moreover, individuals should be provided with "access to the support they may require in exercising their legal capacity."

Sixth, neither the process of assessment nor its outcome should deprive a person of their liberty arbitrarily. "The existence of a disability shall in no case justify a deprivation of liberty" (Article 14 CRPD). What this means in practice, for example, is that disabled persons shall not be detained arbitrarily in assessment centres, required to undergo forced treatment, or be placed in secure institutions on the unsubstantiated opinion of assessors, including arbitrary medical opinion. Deprivation of liberty, by any process, must provide for guarantees in accordance with international law.

Seventh, neither the process of assessment nor its outcome should subject a person to "cruel, inhuman or degrading treatment" and must respect the "physical and mental integrity" of the person (Article 17 CRPD), especially in avoiding bodily interference or harm to health. These issues can be relevant in the context of both medical and functional tests of physical or mental capacity, as well as for work trials and placements to assess an individual's working capacity in context.

Eighth, disability assessments provide access to a wide range of social supports and entitlements, in cash or in kind. Social needs assessments should begin from respect for the right to live independently and to be included in the community (Article 19 CRPD). The scope of assessments should never prejudice "the opportunity to choose [an individual's] place of residence and where and with whom they live" or presume any obligation "to live in a particular living arrangement." It should include consideration of the full range of supports, including personal assistance, as well as access to community facilities.

Ninth, across the range of policy functions, specific eligibility and evaluation criteria in disability assessments should be framed with respect for the relevant substantive rights contained in the CRPD. This will be particularly relevant for assessments conducted in the fields of work and employment (Article 27), and adequate standard of living and social protection (Article 28), as well as education (Article 24). It applies also, for example, to disability assessments impinging on home and family life (Article 23), health (Article 25), and habilitation and rehabilitation (Article 26).

Tenth, the provisions for complaint, review or appeal of assessment decisions, as well as the conduct of the assessment process, should respect a person's right of access to justice (Article 13 CRPD). This means that, amongst other things, in reaching a judgment, there should be "procedural and ageappropriate accommodations, in order to facilitate their effective role as direct and indirect participants" at all stages of proceedings.

Eleventh, in line with the CRPD, appropriate training should be promoted for "professionals and staff" involved in disability assessments "so as to better provide the assistance and services guaranteed by those rights" (Article 4 and 13 CRPD). This might include training in the interactive and contextual 
concept of disability, awareness of disabling barriers and the social model, the CRPD, legal capacity and a person-centred approach. Training is also need for rights holders to participate in self-assessment.

Lastly, and crucially, there should be involvement of disabled people and their organizations, as well as human rights bodies, in the design and regular review of disability assessment systems, as well as the training above. A key claim of the disability rights movement has been "nothing about us without us" and States parties to the CRPD are obliged, under Article 4(3), to "closely consult with and actively involve persons with disabilities, including children with disabilities, through their representative organizations" in all relevant policy decision-making processes, and to involve them in the rights monitoring process (Article 33(3) CRPD).

\section{Conclusion}

This paper drew evidence from a large-scale international study of disability assessments systems. The focus was on European states, but it looked to the global level for guidance on how to align disability assessment procedures with the CRPD. The Convention itself refers only to disability assessments indirectly, but its principles and provisions are directly applicable to this topic, notably to assessments in the social policy field. Since it came into force, over a decade ago, the responsible UN Committee has elaborated on disability assessment more explicitly and extensively.

A CRPD-compatible disability assessment mechanism should balance a social-contextual understanding of disability with a human rights approach. This means that assessments should treat disabled persons as legal rights holders and focus on their interactions with disabling barriers (physical or social) as related to the policy function in question. The CRPD is not incompatible with the technical classification language of the ICF, but it requires close attention to environmental components when making disability assessments. The categorical attribution of disability status based on impairment diagnosis or individual functioning alone is not a CRPD-compatible approach to disability assessment. A CRPD-compatible approach challenges, fundamentally, the historic individualization of disability assessment mechanisms and the widespread medicalization of the professional knowledges that underpin them. Evidence of promising practice shows that change is possible, but this requires the integration of a human rights perspective and the active participation of disabled people, and their organizations, in far-reaching policy review and reform.

Disclosure statement. No potential conflict of interest was reported by the authors.

Funding. The research on which this paper is based was funded by the European Commission under tender JUST/2014/RDIB/ PR/EQUA/0062 and conducted under the auspices of the Academic Network of European Disability experts (ANED). The content of this publication represents the views of the authors only and is their sole responsibility.

Notes on contributors. Lisa Waddington is the European Disability Forum Professor in European Disability Law at the Faculty of Law at Maastricht University (The Netherlands). Her principal area of interest lies in European and comparative disability law, the UN Convention on the Rights of Persons with Disabilities, and European and comparative equality law in general.

Mark Priestley is Professor of Disability Policy in the School of Sociology and Social Policy at the University of Leeds (United Kingdom). He led the scientific programme of the European Commission's Academic Network of European Disability experts (ANED) from its foundation in 2007 until 2019.

\section{References}

Altman, B. M. (2001). Disability definitions, models, classification schemes, and applications. In G. L. Albrecht, K. Seelman, \& M. Bury (Eds.), Handbook of disability studies (pp. 97-122). London, UK: SAGE.

Altman, B. M. (2014). Definitions, concepts, and measures of disability. Annals of Epidemiology, 24(1), 2-7.

Arnould, C., Barral, C., Bouffioulx, E., Castelein, P., Chiriacescu, D., \& Cote, A. (2012). Disability assessment mechanisms: Challenges and issues at stakes for the development of social policies in light of the United Nations Convention for the Rights of 
Persons with Disabilities. Retrieved from Paris: https://www.firah.org/upload/notices2/novembre-2013/synthese_rapport_ firah_-12p-engl.pdf

Barr, B., Clayton, S., Whitehead, M., Thielen, K., Burström, B., Nylén, L., \& Dahl, E. (2010). To what extent have relaxed eligibility requirements and increased generosity of disability benefits acted as disincentives for employment? A systematic review of evidence from countries with well-developed welfare systems. Journal of Epidemiology \& Community Health, 64 (12), 1106-1114.

Bengtsson, S. (2018). Task 2017-18 Disability assessment - Country report, Denmark. Retrieved from Utrecht/Leeds: https:// www.disability-europe.net/downloads/905-country-report-on-disability-assessment-denmark

Bezzina, L., Camilleri-Zahra, A., \& Gauci, V. (2018). Task 2017-18 Disability assessment - Country report, Malta. Retrieved from Utrecht/Leeds: https://www.disability-europe.net/downloads/905-country-report-on-disability-assessment-malta

Bickenbach, J., Posarac, A., Cieza, A., \& Kostanjsek, N. (2015). Assessing Disability in Working Age Population: A Paradigm Shift from Impairment and Functional Limitation to the Disability Approach. Washington, DC: World Bank.

Brage, S., Donceel, P., \& Falez, F. (2008). Development of ICF core set for disability evaluation in social security. Disability and Rehabilitation, 30(18), 1392-1396.

Carter, R. (2017). Decisions are being taken out of our hands'-social workers on care cuts. Community Care (19 September 2017). Retrieved from https://www.communitycare.co.uk/2017/09/19/decisions-taken-hands-social-workers-care-cuts/

Citizens Advice. (2017). Written evidence to the Parliamentary Work and Pensions Committee PIP and ESA Assessments inquiry (PEA0369). Retrieved from http://data.parliament.uk/writtenevidence/committeeevidence.svc/evidencedocument/ work-and-pensions-committee/pip-and-esa-assessments/written/73556.pdf

Committee on the Rights of Persons with Disabilities. (2012). Concluding observations on the initial report of Hungary, CRPD/C/ HUN/CO/1. Retrieved from https://tbinternet.ohchr.org/_layouts/15/treatybodyexternal/Download.aspx?symbolno=CRPD/ $\mathrm{C} / \mathrm{HUN} / \mathrm{CO} / 1$

Committee on the Rights of Persons with Disabilities. (2013). Concluding observations on the initial report of Austria, CRPD/ C/AUT/CO/1. Retrieved from https://tbinternet.ohchr.org/_layouts/15/treatybodyexternal/Download.aspx?symbolno= $\mathrm{CRPD} / \mathrm{C} / \mathrm{AUT} / \mathrm{CO} / 1$

Committee on the Rights of Persons with Disabilities. (2014). Concluding observations on the initial report of Belgium, CRPD/ $C / B E L / C O / 1$. Retrieved from https://tbinternet.ohchr.org/_layouts/15/treatybodyexternal/Download.aspx?symbolno= $\mathrm{CRPD} / \mathrm{C} / \mathrm{BEL} / \mathrm{CO} / 1$

Committee on the Rights of Persons with Disabilities. (2015a). Concluding observations on the initial report of Croatia CRPD/ $\mathrm{C} / \mathrm{HRV} / \mathrm{CO} / 1$. Retrieved from https:/tbinternet.ohchr.org/_layouts/15/treatybodyexternal/Download.aspx?symbolno= $\mathrm{CRPD} / \mathrm{C} / \mathrm{HRV} / \mathrm{CO} / 1$

Committee on the Rights of Persons with Disabilities. (2015b). Concluding observations on the initial report of Czech Republic, CRPD/C/CZE/CO/1. Retrieved from https://tbinternet.ohchr.org/_layouts/15/treatybodyexternal/Download.aspx? symbolno=CRPD/C/CZE/CO/1

Committee on the Rights of Persons with Disabilities. (2015c). Concluding observations on the initial report of Germany $\mathrm{CRPD} / \mathrm{C} / \mathrm{DEU} / \mathrm{CO} / 1$. Retrieved from https://tbinternet.ohchr.org/_layouts/15/treatybodyexternal/Download.aspx?symbolno= $\mathrm{CRPD} / \mathrm{C} / \mathrm{DEU} / \mathrm{CO} / 1$

Committee on the Rights of Persons with Disabilities. (2015d). Concluding observations on the initial report of Mauritius CRPD/C/MUS/CO/1. Retrieved from https://tbinternet.ohchr.org/_layouts/15/treatybodyexternal/Download.aspx?symbolno= $\mathrm{CRPD} / \mathrm{C} / \mathrm{MUS} / \mathrm{CO} / 1$

Committee on the Rights of Persons with Disabilities. (2016a). Concluding observations on the initial report of Italy, CRPD/C/ ITA/CO/1. Retrieved from https://tbinternet.ohchr.org/_layouts/15/treatybodyexternal/Download.aspx?symbolno=CRPD/ $\mathrm{C} / \mathrm{ITA} / \mathrm{CO} / 1$

Committee on the Rights of Persons with Disabilities. (2016b). Concluding observations on the initial report of Lithuania, $C R P D / C / L T U / C O / 1$. Retrieved from https://tbinternet.ohchr.org/_layouts/15/treatybodyexternal/Download.aspx?symbolno= $\mathrm{CRPD} / \mathrm{C} / \mathrm{LTU} / \mathrm{CO} / 1$

Committee on the Rights of Persons with Disabilities. (2016c). Concluding observations on the initial report of Luxembourg, $C R P D / C / L U X / C O / 1$. Retrieved from https://tbinternet.ohchr.org/_layouts/15/treatybodyexternal/Download.aspx?symbolno= $\mathrm{CRPD} / \mathrm{C} / \mathrm{LTU} / \mathrm{CO} / 1$

Committee on the Rights of Persons with Disabilities. (2016d). Concluding observations on the initial report of Portugal, $C R P D / C / P R T / C O / 1$. Retrieved from https://tbinternet.ohchr.org/_layouts/15/treatybodyexternal/Download.aspx?symbolno= $\mathrm{CRPD} / \mathrm{C} / \mathrm{LTU} / \mathrm{CO} / 1$

Committee on the Rights of Persons with Disabilities. (2016e). Concluding observations on the initial report of Serbia, CRPD/ $C / S R B / C O / 1$. Retrieved from https://tbinternet.ohchr.org/_layouts/15/treatybodyexternal/Download.aspx?symbolno= $\mathrm{CRPD} / \mathrm{C} / \mathrm{LTU} / \mathrm{CO} / 1$

Committee on the Rights of Persons with Disabilities. (2016f). Concluding observations on the initial report of Slovakia, CRPD/C/SVK/CO/1. Retrieved from https://tbinternet.ohchr.org/_layouts/15/treatybodyexternal/Download.aspx?symbolno= $\mathrm{CRPD} / \mathrm{C} / \mathrm{LTU} / \mathrm{CO} / 1$ 
Committee on the Rights of Persons with Disabilities. (2017a). Concluding observations on the initial report of Cyprus, CRPD/ C/CYP/CO/1. Retrieved from https://tbinternet.ohchr.org/_layouts/15/treatybodyexternal/Download.aspx?symbolno= $\mathrm{CRPD} / \mathrm{C} / \mathrm{LTU} / \mathrm{CO} / 1$

Committee on the Rights of Persons with Disabilities. (2017b). Concluding observations on the initial report of Latvia, CRPD/ C/LVA/CO/1. Retrieved from https://tbinternet.ohchr.org/_layouts/15/treatybodyexternal/Download.aspx?symbolno= CRPD/C/LTU/CO/1

Committee on the Rights of Persons with Disabilities. (2017c). Concluding observations on the initial report of Montenegro, $C R P D / C / M N E / C O / 1$. Retrieved from https://tbinternet.ohchr.org/_layouts/15/treatybodyexternal/Download.aspx?symbolno= $\mathrm{CRPD} / \mathrm{C} / \mathrm{LTU} / \mathrm{CO} / 1$

Committee on the Rights of Persons with Disabilities. (2017d). Concluding observations on the initial report of United Kingdom, CRPD/C/GBR/CO/1. Retrieved from https://tbinternet.ohchr.org/_layouts/15/treatybodyexternal/Download. aspx?symbolno=CRPD/C/LTU/CO/1

Council of Europe. (2002). Assessing Disability in Europe - Similarities and Differences: Report Drawn up by the Working Group on the Assessment of Person-Related Criteria for Allowances and Personal Assistance for People with Disabilities (Partial Agreement) (P-RR-ECA). Strasbourg, France: Council of Europe Publishing.

David, H., \& Duggan, M. G. (2006). The growth in the social security disability rolls: A fiscal crisis unfolding. Journal of Economic Perspectives, 20(3), 71-96.

De Bruycker, S. (2018). Task 2017-18 Disability assessment - Country report, Belgium. Retrieved from Utrecht/Leeds: https:// www.disability-europe.net/downloads/905-country-report-on-disability-assessment-belgium

de Wind, A. E.,Dekkers-Sánchez, P. M., \& Godderis, L. (2016). The role of European physicians in the assessment of work disability: A comparative study. Edorium Journal of Disability and Rehabilitation, 2, 78-87.

Degener, T. (2016). Disability in a human rights context. Laws, 5(3), 35.

Degener, T. (2017). A new human rights model of disability. In V. D. Finna, R. Cera, \& G. Palmisano (Eds.), The United Nations Convention on the Rights of Persons with Disabilities: A Commentary (pp. 41-59). Oxford, UK: Oxford University Press.

Diels, V., \& Van Puyenbroeck, J. (2015). Onderzoek naar de validiteit van het IZIKA en IZIIK instrument voor de doelgroep kinderen en jongeren met een handicap. Retrieved from https://praktijkgerichtonderzoek.odisee.be/sites/default/files/ mediabestanden/izika_rapport_251115.pdf

Finkelstein, V. (2001). The social model of disability repossessed. Retrieved from Leeds: http://disability-studies.leeds.ac.uk/ wp-content/uploads/sites/40/library/finkelstein-soc-mod-repossessed.pdf

Fleischer, D. Z., \& Zames, F. (2005). Disability rights: The overlooked civil rights issue. Disability Studies Quarterly, 25(4). Retrieved from https://dsq-sds.org/article/view/629/806

Flieger, P., \& Naue, U. (2018). Task 2017-18 Disability assessment - Country report, Austria. Retrieved from Utrecht/Leeds: https://www.disability-europe.net/downloads/905-country-report-on-disability-assessment-austria

Fougeyrollas, P., Noreau, L., \& Boschen, K. (2002). Interaction of environment with individual characteristics and social participation: Theoretical perspectives and applications in persons with spinal cord injury. Topics in Spinal Cord Injury Rehabilitation, 7(3), 1-16.

Francescutti, C. (2011). UN convention on the rights of persons with disability, eligibility criteria and the International Classification of Functioning Disability and Health. BMC Public Health, 11(S4), S1.

Francescutti, C., Gongolo, F., Simoncello, A., \& Frattura, L. (2011). Description of the person-environment interaction: Methodological issues and empirical results of an Italian large-scale disability assessment study using an ICF-based protocol. BMC Public Health, 11, S11.

Garsten, C., \& Jacobsson, K. (2013). Sorting people in and out: The plasticity of the categories of employability, work capacity and disability as technologies of government. Ephemera: Theory \& Politics in Organisation, 13(4), 825-850.

Gyulavári, T., \& Horváth, P. L. (2018). Task 2017-18 Disability assessment - Country report, Hungary. Retrieved from Utrecht/ Leeds: https://www.disability-europe.net/downloads/905-country-report-on-disability-assessment-hungary

International Labour Organisation, \& International Disability Alliance. (2019). Joint statement: Towards inclusive social protection systems supporting the full and effective participation of persons with disabilities. Retrieved from https://www. social-protection.org/gimi/gess/RessourcePDF.action?ressource.ressourceId=55473

Kakoullis, E., \& Ikehara, Y. (2018). Article 1 purpose. In I. Bantekas, M. Stein, \& D. Anastasiou (Eds.), The Convention on the Rights of Persons with Disabilities A Commentary. Oxford, UK: Oxford University Press.

Kanter, A. S. (2003). The globalization of disability rights law. Syracuse Journal of International Law and Commerce, 30, 241.

Kayess, R., \& French, P. (2008). Out of darkness into light? Introducing the convention on the rights of persons with disabilities. Human Rights Law Review, 8(1), 1-34.

Kazou, K. (2017). Analysing the definition of disability in the UN Convention on the rights of persons with disabilities: Is it really based on a 'Social Model' approach? International Journal of Mental Health and Capacity Law, 2017(23), 25-48.

Kelemen, R. D., \& Vanhala, L. (2010). The shift to the rights model of disability in the EU and Canada. Regional \& Federal Studies, 20(1), 1-18.

Lawson, A. (2006). The United Nations Convention on the Rights of Persons with Disabilities: New era or false dawn? Syracuse Journal of International Law and Commerce, 34, 563. 
Mabbett, D. (2005). Some are more equal than others: Definitions of disability in social policy and discrimination law in Europe. Journal of Social Policy, 34(2), 215-233.

Madden, R., Glozier, N., Mpofu, E., \& Llewellyn, G. (2011). Eligibility, the ICF and the UN Convention: Australian perspectives. BMC Public Health, 11, S6.

Nicolas, C., \& Ebersold, S. (2018). Task 2017-18 Disability assessment - Country report, France. Retrieved from Utrecht/Leeds: https://www.disability-europe.net/downloads/905-country-report-on-disability-assessment-france

Office of the High Commissioner for Human Rights. (n.d.). Treaty body database. Retrieved from https://tbinternet.ohchr.org Oliver, M. (1990). Politics of Disablement. London, UK: Macmillan.

Oliver, M. (1995). Understanding Disability: From Theory to Practice. London, UK: Macmillan International Higher Education. Oliver, M., \& Barnes, C. (2012). The New Politics of Disablement. London, UK: Macmillan.

Podzina, D. (2018). Task 2017-18 Disability assessment - Country report, Latvia. Retrieved from Utrecht/Leeds: https:// www.disability-europe.net/downloads/905-country-report-on-disability-assessment-latvia

Pozzo, C. D., Haines, H., Laroche, Y., Fratello, F., \& Scorretti, C. (2002). Assessing Disability in Europe - Similarities and Differences Strasbourg, France: Council of Europe Publishing.

Priestley, M. (1998). Discourse and resistance in care assessment: Integrated living and community care. The British Journal of Social Work, 28(5), 659-673.

Quinn, G., Degener, T., Bruce, A., Burke, C., Castellino, J., Kenna, P., Kilkelly, U., \& Quinlivan, S. (2002). The current use and future potential of United Nations human rights instruments in the context of disability. New York and Geneva: Office of the United Nations High Commissioner on Human Rights.

Rioux, M., \& Carbert, A. (2003). Human rights and disability: The international context. Journal on Developmental Disabilities, 10, 1-13.

Secrétaire d'Etat auprès du Premier ministre chargée des Personnes handicapées. (n.d.). Maison Départementale des Personnes Handicapées (MDPH). Retrieved from https://handicap.gouv.fr/les-aides-et-les-prestations/maison-departementale-duhandicap/article/maison-departementale-des-personnes-handicapees-mdph

Šiška, J. (2018). Task 2017-18 Disability assessment - Country report, Czech Republic. Retrieved from Utrecht/Leeds: https:// www.disability-europe.net/downloads/904-country-report-on-disability-assessment-czech-republic

Stein, M. A., \& Stein, P. J. (2006). Beyond disability civil rights. Hastings Law Journal, 58, 1203.

Stone, D. A. (1985). The Disabled State. London, UK: Macmillan.

Union of the Physically Impaired Against Segregation. (1976). Fundamental Principles of Disability: Being a Summary of the Discussion Held on 22nd November, 1975 and Containing Commentaries from Each Organisation. London, UK: Union of the Physically Impaired Against Segregation.

Üstïn, T., Kostanjsek, N., Chatterji, S., \& Rehm, J. (Eds.). (2010). Measuring Health and Disability, Manual for WHO Disability Assessment Schedule, WHODAS 2.0. Geneva, Switzerland: World Health Organization

Üstün, T. B., Chatterji, S., Kostanjsek, N., Rehm, J., Kennedy, C., Epping-Jordan, J., Saxena, S., von Korff, M., \& Pull, C. (2010). Developing the World Health Organization disability assessment schedule 2.0. Bulletin of the World Health Organization, 88, 815-823.

Vanhala, L. (2015). The diffusion of disability rights in Europe. Human Rights Quarterly, 37, 831-853.

Waddington, L. (2009). Breaking new ground: The implications of ratification of the UN Convention on the rights of persons with disabilities for the European Community. In O. M. Arnardóttir \& G. Quinn (Eds.), The UN Convention on the Rights of Persons with Disabilities: European and Scandinavian Perspectives (pp. 111-140). Leiden, Netherlands: Martinus Nijhoff Publishers.

Waddington, L., Priestley, M., \& Sainsbury, R. (2018). Disability Assessment in the European States. Utrecht, Netherlands: Academic Network of European Disability experts.

Cite this article: Waddington, L. and Priestley, M. (2021). A human rights approach to disability assessment. Journal of International and Comparative Social Policy 37: 1-15. https://doi.org/10.1017/ics.2020.21 